\title{
Extrinsic Factors Driving Oligodendrocyte Lineage Cell Progression in CNS Development and Injury
}

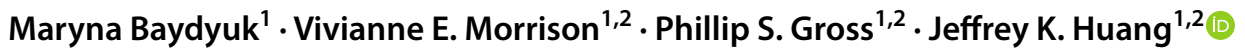

Received: 13 September 2019 / Revised: 19 December 2019 / Accepted: 21 December 2019 / Published online: 29 January 2020

(c) The Author(s) 2020

\begin{abstract}
Oligodendrocytes (OLs) generate myelin membranes for the rapid propagation of electrical signals along axons in the central nervous system (CNS) and provide metabolites to support axonal integrity and function. Differentiation of OLs from oligodendrocyte progenitor cells (OPCs) is orchestrated by a multitude of intrinsic and extrinsic factors in the CNS. Disruption of this process, or OL loss in the developing or adult brain, as observed in various neurological conditions including hypoxia/ ischemia, stroke, and demyelination, results in axonal dystrophy, neuronal dysfunction, and severe neurological impairments. While much is known regarding the intrinsic regulatory signals required for OL lineage cell progression in development, studies from pathological conditions highlight the importance of the CNS environment and external signals in regulating OL genesis and maturation. Here, we review the recent findings in OL biology in the context of the CNS physiological and pathological conditions, focusing on extrinsic factors that facilitate OL development and regeneration.
\end{abstract}

Keywords Oligodendrocytes · Oligodendrocyte precursor cells (OPCs) · Myelin · Demyelination · Remyelination · Diffuse white matter injury $\cdot$ Multiple sclerosis

\section{Introduction}

The central nervous system (CNS) integrates and processes an immense amount of information leading to complex behavior. This multilevel process requires an extensive network of neural cell types to be established and maintained. During embryonic CNS development, progenitor pools of neuronal and glial cells expand and differentiate to acquire relevant functions. Oligodendrocytes (OLs) are glial cells whose terminal processes generate myelin and enwrap CNS axons. Myelin is crucial for saltatory propagation of electrical impulses down the axon, enabling rapid communication between networks of neurons in the CNS [1]. In addition to increasing axonal conduction speed through generating myelin, OLs secrete metabolic factors and maintain energy

Special Issue: In Honor of Professor Vittorio Gallo.

Jeffrey K. Huang

jh1659@georgetown.edu

1 Department of Biology and Center for Cell Reprogramming, Georgetown University, Washington, DC 20057, USA

2 Interdisciplinary Program in Neuroscience, Georgetown University, Washington, DC 20057, USA homeostasis to support axonal integrity and promote neuronal survival [2]. Thus, establishing proper numbers of OLs during brain development, as well as during their regeneration in neurological disorders that involve OL and myelin loss, is crucial for normal CNS function.

During CNS development, oligodendrocyte progenitor cells (OPCs) are generated from neural stem/progenitor cells (NSPCs) in several regions in a precise spatiotemporal manner [3-5]. Multiple transcriptional regulators cooperate to orchestrate changes in gene expression leading to OPC fate selection and subsequent differentiation to oligodendrocytes. One of the most important regulators of OL lineage cell development is oligodendrocyte transcription factor 2 (Olig2), which acts as a central node upon which numerous pathways converge and from which foundational intrinsic signals arise to drive OPC genesis and maturation $[3,4$, 6-8]. For example, the $\mathrm{Wnt} / \beta$-catenin and bone morphogenic protein (BMP) pathways inhibit Olig2 gene function [9-11], while fibroblast growth factor (FGF), sonic hedgehog (SHH), retinoic acid (RA), and Notch1 signaling increase Olig2 expression, facilitating OPC production, proliferation, and maturation [9, 12-14]. Once generated, transcriptional regulators such as Myrf, Myt, RXRs, are required for the differentiation of OPCs into oligodendrocytes [15-19]. 
Details of intrinsic signals regulating oligodendrocyte lineage cell specification and progression are well described elsewhere $[4,15,16,20]$ and will not be discussed further here. However, since OLs are part of an exquisitely complex CNS environment containing neurons, astrocytes, microglia, and vascular/perivascular cells, control of OL lineage cell proliferation and differentiation likely relies on multiple extrinsic cues and cell-cell interactions during development or regeneration. Here we will discuss the role of extrinsic factors in regulating the progression of OL lineage cells from immature, migrating precursors to fully differentiated, myelinating oligodendrocytes in development, aging, and disease (Fig. 1).

\section{Neuronal Regulation of OL Development}

Since activity-dependent myelination was proposed over five decades ago [15], research focusing on neuronal regulation of OL development and function has revealed various pathways that might affect oligodendrocyte lineage progression from OPC proliferation to the terminal myelinating stage [15, 21-24]. Increasing evidence shows that neuronal activity and glutamate signaling can promote OPC migration, proliferation, differentiation, and myelination during development [21, 25-30]. OPCs receive synaptic inputs from neurons and express voltage-gated ion channels (such as voltage-gated sodium and potassium channels) and various neurotransmitter receptors [25, 27, 28, 31, 32]. Activation of voltage-gated sodium channels on OPCs leads to an increased number of proliferating OPCs and mature OLs [21, 33, 34], while potassium channel currents are known to enhance proliferation but may delay differentiation $[32,35$,

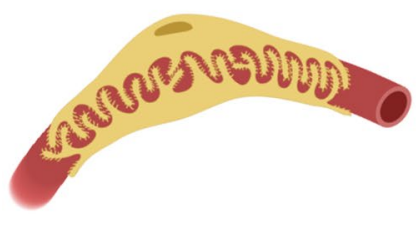

Vascular/perivascular signals: Astrocyte-derived growth factors:

- $\Uparrow$ OPC specification

- $\uparrow$ migration

- $\Uparrow$ differentiation

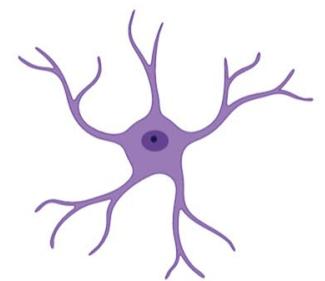

- $\Uparrow$ p proliferation

- $\sqrt{ }$ differentiation

- $\Uparrow$ survival

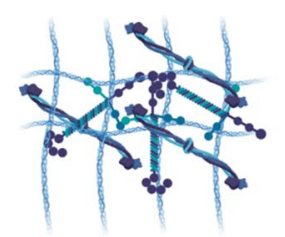

Extracellular matrix:

- potentiation of growth factor signaling - differential regulation of proliferation and differentiation
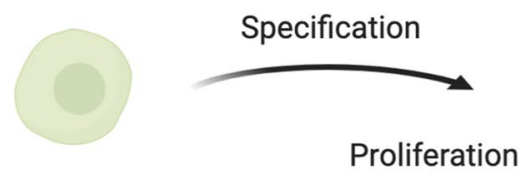

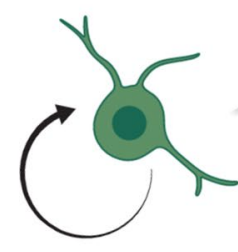

\section{Differentiation}

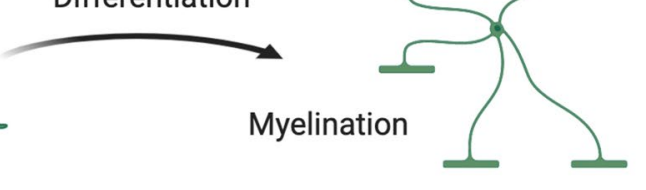

Neuronal activity and neurotransmitters:

- differential OPC voltage-gated channel activation

- differential calcium signaling

- $\Uparrow$ migration

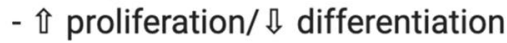

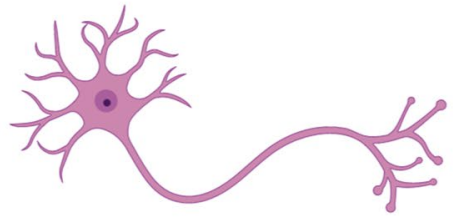

Microglia-derived cytokines:

- potentiation of astrocyte-derived growth factor secretion - $\uparrow$ maturation and (re)myelination

- $\Uparrow$ OPC death following injury
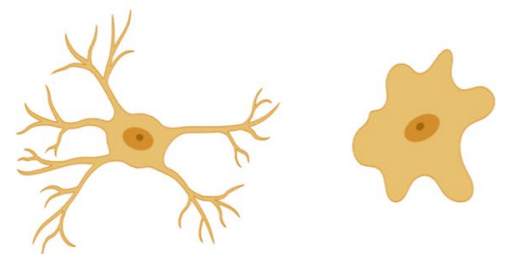

Fig. 1 Extrinsic regulators of oligodendrocyte lineage cell progression from immature, migrating precursors to fully differentiated, myelinating oligodendrocytes 
36]. Glutamate released by excitatory neurons may serve as a chemoattractant, stimulating the migration of OPCs toward their target destination in the developing brain [26]. Activation of glutamate receptors on OPCs accelerates integrinmediated OPC motility via mechanisms that involve AMPA receptors [26]. Glutamate signaling in OPCs also leads to potassium channel inhibition and decreased OPC proliferation [32]. The molecular mechanisms underlying glutamate signaling in OPCs involve elevated levels of the cell cycle inhibitors $\mathrm{p} 27^{\mathrm{Kip} 1}$ and $\mathrm{p} 21^{\mathrm{Cip} 1}$ [37-39], both of which naturally rise with continued OPC proliferation, constituting an "internal clock" or timing component of OL lineage cell progression and leading to stalling at the G1-S phase transition by dissociating cyclin-cdk complexes [35, 40-42]. These cell cycle inhibitors require thyroid hormone for their function and may, in turn, facilitate OPC maturation by triggering histone deacetylase-mediated changes in OPC gene function [42-46].

Activation of glutamate receptors on OPCs can also initiate local translation of myelin basic protein (MBP) and increase calcium transients in OPC/OL [47-49]. This process aligns with the observation that functionally active neurons are preferentially myelinated, while inhibition of glutamate release from a given axon decreases its likelihood of becoming myelinated [50-53]. It appears that some myelinated tracks rely on glutamatergic signals to induce myelination, while others do not. For instance, loss of vesicular glutamate release from reticulospinal neurons decreases their myelination, but similar loss in commissural ascending fibers has no impact on myelin [54]. This heterogeneity in the requirement of glutamate for myelination is not completely surprising, however, because while some myelinated regions contain exclusively glutamatergic projections (e.g. the corpus callosum), others contain a mixture of glutamatergic and GABAergic neurons. In addition to glutamate, OPCs can also respond to GABA. The impact of GABA signaling on OPCs depends on the type of GABA receptors that the cells express. For example, $\mathrm{GABA}_{\mathrm{A}}$ receptor activation slows OPC proliferation and the extent of myelination, though curiously, the myelinated internodes formed by the GABA-stimulated cell are longer than those of non-GABAstimulated cells [55]. Conversely, activation of $\mathrm{GABA}_{\mathrm{B}}$ receptors stimulates OPC proliferation and migration [56]. The dynamics of axonal neurotransmitter release and receptor activation in OPCs are still largely unknown and further research is needed to fully uncover neuronal regulation of OL development.

Activity-dependent regulation of OL recruitment, lineage progression, and de novo myelination is evident from behavioral paradigms of motor learning. It has been shown that in mice learning to run on the complex wheel there is rapid differentiation of OPCs in the motor cortex, followed by a subsequent increase in compensatory proliferation to return to homeostatic OPC density [57-59]. Blocking OPC differentiation impedes motor learning and performance on the complex wheel [58]. Similarly, improvements in rodent spatial learning parallel increasing levels of OPC proliferation, myelination, and corpus callosum volume, and this effect is amplified by environmental enrichment [60]. Conversely, it has been demonstrated that social isolation of adult or early postnatal mice results in significant behavioral, transcriptional, and ultrastructural changes in OLs of the prefrontal cortex $[61,62]$. Interestingly, these changes can be reversed by social reintegration in adult mice, however, the lack of social experience in juvenile mice during the critical period of prefrontal cortex development cannot be reversed by social reintroduction at later time points $[61$, 62]. These studies imply that activation of various neuronal circuits play an important role in white matter development (Fig. 1), while inhibition of neuronal activity may lead to myelin deficits [63].

\section{Role of Astrocytes in OL Maturation}

Astrocytes precede OL in early postnatal development and regulate OPC proliferation, migration, survival, and differentiation through secreted factors such as PDGF, FGF, leukemia inhibitory factor (LIF), and a member of the interleukin (IL)-6 cytokine family [64-69]. When astrocytes fail to mature, i.e. in Gfap null mice, the lack of released growth factors cause white matter dysplasia and altered myelination [70], demonstrating that normal white matter development requires astrocytes. Mice with global PDGF deletion have a reduced number of OPCs and subsequent hypomyelination [71], whereas overexpression of PDGF in astrocytes of the mouse optic nerve leads to OPC hyperplasia [72]. Although, factors released by astrocytes often work in cooperation, they may also differentially regulate certain processes in $\mathrm{OL}$ development. For instance, PDGF applied in vitro prevents morphological maturation of OPCs, but cannot keep the cell in a constant proliferative state [73]. In contrast, FGF alone allows morphological maturation, but keeps the OPC in the cell cycle, albeit with a much-lengthened cell cycle time [73]. However, when both growth factors are present, OPCs can maintain an immature morphology and sustain proliferative capacity [73]. Similarly, the combination of PDGF and LIF promotes OPC survival, and while decrease in PDGF $\alpha$-receptor signaling seems to be required for differentiation, continued LIF signaling in OLs stimulates myelination [68, 69].

Another soluble astrocyte-derived signal is endothelin-1 (ET-1), which has been shown to regulate OPC migration and differentiation [74]. Several isoforms of endothelins (ET-1, 2, and 3) are present in many tissues, including the brain at varying levels, and are also secreted by endothelial 
cells of microvasculature [75]. ETs induce their signaling through activation of their specific receptors (ETHRA and ETHRB), which are expressed by OPCs [74, 76]. Activation of ETHRs by ET-1 was found to play a dual role in early developmental stages in OL lineage progression by promoting OPC migration, while inhibiting their differentiation [74]. Interestingly, ET-1 alone did not promote OPC migration; instead it augmented the stimulatory effects of PDGF and FGF, possibly by facilitating the intracellular pathways activated by these growth factors in OPCs [74]. In contrast, ET-1 alone inhibited OPC progression to mature OLs by reducing differentiation of OPCs in the postnatal brain [74]. This observation is consistent with OL lineage progression, since OPC migratory potential decreases as they differentiate into mature myelin-producing OLs.

Astrocytes have also been shown to influence OL biology through secretion of extracellular matrix (ECM) proteins such as fibronectin and laminin [77]. Early in vitro studies demonstrated that fibronectin stimulated the migration and proliferation of OPCs via interaction with integrin receptors $\alpha v \beta 1$ and $\alpha v \beta 3$, respectively [78, 79]. Subsequent studies revealed an important role of a crosstalk between fibronectin and growth factor signaling by demonstrating that activation of the $\alpha v \beta 3$ integrin receptor via fibronectin binding can potentiate the proliferative response elicited by the mitogenic growth factor PDGF-A [80, 81]. Moreover, both ECM proteins, fibronectin and laminin, have been shown to promote oligodendrocyte process extension by potentiating FGF2 [81, 82] in a protein kinase C (PKC)-dependent manner [83]. Taken together these and other studies demonstrate the importance of multiple astrocyte-derived factors on all aspects of OL biology (Fig. 1).

\section{Effect of Microglia on OPCs}

Microglia are traditionally considered the resident immune cell population of the CNS, able to survey the tissue and attack pathogens and clear debris from normal, developmental apoptosis. We are just beginning to understand the integral role of microglia in brain development and function throughout life, specifically in the context of OL biology. A recent study shows that depletion of microglia ex vivo and in vivo does not affect OPC number in adult tissues, suggesting that microglia are not essential for OPC viability postnatally [84]. However, microglia activation, i.e. under injury conditions, appears to influence oligodendrocyte lineage cell progression [85]. Following activation with a proinflammatory stimulus, application of microglia-conditioned media (MCM) to myelinating co-cultures, while less effective at sustaining OPC viability than astrocyte-conditioned media, greatly increases the number of mature $\mathrm{CC}^{+}, \mathrm{MBP}^{+} \mathrm{OLs}$ and myelinated fibers $[86,87]$. However, it is not possible to discern whether these pro-differentiation changes result from direct interactions of OPCs with microglial secreted factors or from indirect effects downstream of changes in other cell types such as astrocytes and neurons. The secreted factors in MCM that influence OPC development directly or through other cell types (such as astrocytes) appear to be largely cytokines and vary depending on the microglial activation state. For example, IL-1b, IL-6 family cytokines, and TNFa act through astrocytes to enhance OPC differentiation, by stimulating LIF transcription and secretion [88, 89]. Additionally, loss of TNFR signaling decreases CXCL12-CXCR4 interactions between astrocytes and OPCs, respectively, thereby decreasing OPC proliferation and differentiation [90].

In vivo, high numbers of activated microglia are observed in the SVZ between postnatal day 1 (P1) and P10, which corresponds to peak OPC specification from SVZ-resident NPSCs [91]. Similar observations were made in the postnatal corpus callosum (CC), where peak microglial numbers coincided with peak OPC turnover in the CC and many microglia were found to contain myelin debris [92], suggesting a role for microglia in subcortical white matter OPC homeostasis.

\section{Role of Vascular and Perivascular Cells in Oligodendrogenesis}

Angiogenesis in the brain begins around embryonic day 10 (E10), when pericytes and other fibroblast-like cells and blood vessels penetrate the brain parenchyma, with the former developing into heterogeneous perivascular cell populations found in the postnatal brain [93-96]. Interestingly, angiogenesis in the CC continues well into the first two weeks of postnatal life, suggesting a connection between OPC development and the vasculature [97]. Indeed, there is a possibility that endothelial cells in the perineural vascular plexus surrounding the neurogenic niches of the forebrain [98] interact with neural precursors to drive OPC specification [99]. Similarly, endothelial cell-conditioned media provides trophic and pro-OPC specification cues for neural precursors and OPCs in vitro $[100,101]$. The CNS vascular niche is composed of endothelial cells as well as perivascular cells that adhere to the blood vessels. It has been shown that pericyte-conditioned media applied to neurospheres increases Olig2 mRNA and decreases transcription of the astrocyte-determinant $I d 2$, ultimately favoring OPC specification over the astrocyte lineage [102]. Intriguingly, recent studies have found that OPCs use blood vessels as a scaffold for migration in the developing CNS [103]. The vascular and perivascular cells are located in close proximity to OPCs and can influence OPC proliferation and migration through both contact-dependent signals and secreted factors [103-105]. 
It was found that internalization of microvessel-derived extracellular vesicles promotes OPC survival, migration, and proliferation [106, 107]. This mechanism requires binding of vesicular protein fibronectin to heparan sulfate proteoglycan on OPCs [107]. Similarly, PDGF-dependent effects on OPC proliferation requires the expression of chondroitin sulfate proteoglycan 4/neural-glial antigen 2 (CSPG4/NG2) on the OPC cell surface [108-112]. Mice lacking NG2 fail to expand their OPC population [113, 114]. The epidermal growth factor (EGF) and vascular endothelial growth factor A (VEGFA) bind to their receptors on OPCs, EGFR, and VEGFR, respectively, and activate intracellular signaling, driving OPC migration [115-118]. Interestingly, there is a mutually beneficial relationship between OPCs and the vascular/perivascular population: OPCs regulate angiogenesis and pericyte colonization of the vasculature, while blood vessels and their associated cells support OPC proliferation, survival, and migration [97, 104, 117]. These studies also suggest that mild hypoxia in the perinatal white matter is not categorically detrimental, but rather may be a necessary part of OPC development and myelination, since loss of hypoxiainducible factor signaling in OPCs leads to angiogenic failure and loss of white matter integrity in the developing brain [97].

Following demyelinating injury, OPCs are recruited into the lesion site via single cell perivascular migration on microvessels [119], similar to their developmental route, where OPCs require a vascular scaffold for their dispersal through the CNS. Recently, it has been shown that in multiple sclerosis (MS) lesions with active inflammation, OPCs can be found clustered on vasculature, representing a defect in single cell perivascular migration and inability to detach from blood vessels [119]. Interestingly, OPC perivascular clusters themselves can cause endothelial disruption and defects in blood-brain barrier integrity, triggering a subsequent CNS inflammation and contributing to pathology [119]. These findings suggest that oligodendroglial-vascular interaction is an important component regulating OPC migration and recruitment in developing and adult brain.

\section{Effect of Hypoxia on OPCs}

Alterations in white matter development due to neonatal brain damage are often associated with significant delays and disruption of myelination, correlating with a period of maturation-dependent vulnerability of OPCs immediately before progressing to OLs [120-122]. One of the most common developmental impairments caused by hypoxia-ischemia in premature neonates is diffuse white matter injury (DWMI), which is associated with permanent neurological disabilities [123]. Identification of molecular mediators of OL regeneration in neonatal white matter following hypoxia is essential for developing therapeutic strategies to prevent neurodevelopmental deficits associated with this pathology in premature infants. Several studies using animal models of neonatal hypoxia-ischemia induced brain injury, which reproduce morphological and structural brain abnormalities found in DWMI, demonstrate biphasic changes in white matter, which start with OL death by apoptosis, followed by OPC proliferation during the first week after hypoxia, and resulting in delayed OL differentiation and abnormal myelination $[123,124]$. The cellular and molecular mechanisms essential for the regenerative OPC responses after hypoxia involve activation of the $\mathrm{Cdk} 2$ signaling pathway, which promotes OPC proliferation [42, 125]; and reduction in expression level of $\mathrm{p} 27^{\mathrm{Kip} 1}$ and its regulator FoxO1, resulting in delayed differentiation of OPCs [124]. In agreement with these findings in animal model, $\mathrm{p} 27^{\mathrm{Kip} 1}$ was also reduced in OPCs found in human infant white matter lesions after hypoxia [124]. Later studies identified the histone deacetylase Sirt1 as a $\mathrm{Cdk} 2$ regulator of OPC proliferation in response to hypoxia [126]. Sirt1, which is specifically upregulated in proliferating OPCs after hypoxic insult, targets members of the Cdk2 pathway, causing epigenetic changes that drive Cdk2-mediated OPC proliferation [126].

Other studies have shown that signaling via epidermal growth factor receptor (EGFR) play important roles in OL development and regeneration [110, 118]. In mouse models of chronic neonatal hypoxia, a significant increase in the endogenous EGF levels was observed in the white matter [127]. Moreover, in these models, enhanced EGFR signaling stimulates the endogenous response of OPCs during a critical period after brain injury and promotes cellular and behavioral recovery in the developing brain [127]. Overexpression of human EGFR in oligodendrocyte lineage cells or the administration of intranasal EGF immediately after injury decreased oligodendroglia death, enhanced generation of new OLs, diminished ultrastructural myelin deficiency, and promoted functional recovery [127]. Since there are no clinically relevant treatments available to improve neurological outcomes of neonates with DWMI, molecular manipulations of the pathways that selectively enhance OL regeneration during a critical developmental time window after DWMI may serve as promising targets for promoting timely repair.

\section{Role of Inflammation in Oligodendrocyte Cell Lineage Progression}

One of the most common demyelinating disorders of the adult CNS is multiple sclerosis (MS). In MS, damage to the white matter, caused by repeated immune-mediated attacks and destruction of myelin, results in neurodegeneration and progressive disability [128-132]. In the early 
stage of MS, endogenous CNS repair through remyelination takes place following demyelination and involves the recruitment, proliferation, and differentiation of oligodendrocyte precursor cells (OPCs) into myelin-producing oligodendrocytes [133, 134]. However, in the later, progressive stage, this regenerative process fails and most lesions remain demyelinated, leading to chronic axonal dysfunction and clinical deterioration [133-138]. The mechanisms that lead to remyelination failure in MS remain unknown. However, it has been shown that stalled OPC differentiation is caused by inhibitory signals present in the pathological lesion environment in patients with progressive MS $[133,135,139]$. Identification of these signals is essential to promote OPC differentiation and lesion repair.

The ability of progenitor cell populations to repair damaged tissue is modified by various growth factors, cytokines, and other intracellular signaling molecules, produced by many cell types present at the lesion site after demyelinating injury. During initial stages of demyelination, the highly inflammatory environment consists of reactive astrocytes, T-cells, pro-inflammatory macrophages and activated microglia, which secrete factors that promote OPC recruitment and proliferation [132]. At later stages of lesion progression, the inflammatory responses subside, resulting in OPC differentiation and myelin production [133, 134]. It is essential to understand how specific signals, produced by different cell types in the lesion, impact repair processes for further development of targeted approaches to enhance the beneficial responses that favor remyelination, while preventing the deleterious ones which inhibit it [139].

In addition to the previously discussed functions of astrocytes in OL development, astrocytes, depending on their activation state, can play an opposing role in OL remyelinating potential under injury conditions [77, 140]. Astrocytes display a continuum of phenotypes, ranging from the quiescent to more activated or reactive state, which can modulate myelination positively or negatively. For instance, in myelinating culture system, the presence of quiescent astrocytes, induced by tenascin C through CXCL10, results in less myelinated fibers [141], while activation of astrocytes through treatment with the cytokine, ciliary neurotrophic factor (CNTF), promotes myelination [141]. Conversely, astrocytes that have a severe reactive phenotype, induced by proinflammatory cytokines and CNS tissue damage, may secrete cytokines and chemokines that lead to myelin and oligodendrocyte damage, suppress remyelination, and delay disease recovery in animal models of demyelination [77, 140]. These studies demonstrate a direct correlation of astrocyte phenotypes with their ability to support remyelination and might have important implications with respect to the development of therapeutic strategies to promote CNS remyelination in demyelinating diseases.
Previous studies have shown that in addition to regulating OL development, astrocyte-derived factor, ET-1, also played an important role in OL repair responses after demyelinating insult, by inhibiting OPC differentiation and remyelination through activation of Notch signaling [142]. Previous studies have also shown that Notch1 inhibits OPC differentiation during both development and remyelination [143, 144]. Although astrocytes are not the only cells that produce and express ET-1, the largest increase in ET-1 expression was found in astrocytes following lysolecithin-induced focal demyelination and in MS lesions [142]. Moreover, infusion of exogenous ET-1 in mice during remyelination limited OPC differentiation, while selective genetic ablation of ET-1 in astrocytes significantly increased the number of mature OLs in focal demyelinated lesions and shifted the OL ratio from an immature to mature phenotype [142]. These findings indicate that astrocyte-derived ET-1 acts as an inhibitor of OPC differentiation and remyelination.

Endothelin receptors, EDNRA and EDNRB are upregulated after demyelination and are expressed by both reactive astrocytes and OPCs [74, 145]. However, it has been shown that ET-1 signaling through EDNRB, but not EDNRA, accelerates remyelination [146]. Moreover, selective EDNRB loss in astrocytes accelerated OPC differentiation, OL regeneration, and increased myelin production, whereas deletion of Ednrb in OPCs had no effect [146]. Together, these results demonstrate that reactive astrocytes indirectly inhibit OPC differentiation through ET-1 signaling.

The innate immune response to demyelination in the CNS that is comprised of peripherally derived macrophages and CNS residing microglia can potently influence OL differentiation and remyelination in the lesion [85]. The importance of macrophages/microglia is demonstrated by impaired remyelination following their depletion [147]. Two possible mechanisms, by which macrophages/microglia enhance remyelination are known: the clearance of myelin debris which is known to inhibit repair or secretion of regenerative factors such as cytokines [86, 148, 149]. Notably, macrophages/microglia can be polarized to distinct functional phenotypes: proinflammatory (M1) or anti-inflammatory/ immunoregulatory (M2) [85, 86]. M1 'classically activated' phenotypes are associated with enhanced antigen presentation properties and secretion of pro-inflammatory cytokines and reactive oxygen/nitrogen species, while M2 are thought to secrete anti-inflammatory cytokines/growth factors [150]. It has been proposed that as remyelination begins in the lesion, the switch from dominant M1 to M2 can occur within microglia and peripherally-derived macrophages. It has been shown that M2 macrophages/microglia are an essential part of an effective remyelination response, driving oligodendrocyte differentiation during lesion repair [86]. This M2-driven regenerative response is mediated, at least in part, by secretion of the TGF $\beta$ superfamily member, 
activin-A, and activates the mammalian target of rapamycin (mTOR) pathway, which has been previously implicated in positively regulating oligodendrocyte differentiation and/or myelination [85, 86, 151]. However, the M1 and M2 phenotypes represent a very simplistic view of macrophage/microglial phenotypes. More recent studies using newly developed technologies such as RNAseq, quantitative proteomics, and epigenetic approaches, have identified diverse populations of macrophages and microglia in health and disease, redefining our view of the complexity of immune cells in the CNS in physiological and pathological conditions [152-154]. These studies have characterized unique signature profiles of homeostatic and disease-associated subpopulations of tissue-derived macrophages and CNS microglia, uncovering their transcriptional identity and highlighting shifts in these population contributions in various neurological disorders.

Several macrophages/microglia populations have been shown to secrete the enzyme interleukin-four induced one (IL4I1), which is upregulated at the onset of inflammation resolution and remyelination [155]. Mice lacking Il4il or its receptor show increased proinflammatory macrophage density, remyelination impairment, and axonal injury in the CNS lesions. Conversely, recombinant IL4I1 administration reduces proinflammatory macrophage density, enhances remyelination, and rescues remyelination impairment [155]. Remarkably, intravenous injection of IL4I1 into mice with experimental autoimmune encephalomyelitis (a widely used inflammatory mouse model of MS) at disease onset significantly reversed disease severity, resulting in motor function recovery [155]. These studies suggest that manipulating M2 polarization and secretion of pro-myelinating factors in the CNS lesion may present a complementary regenerative strategy to support remyelination and clinical recovery in MS.

Increasing evidence suggests that the immune cytokine interferon-gamma (IFN- $\gamma$ ), secreted by activated T-lymphocytes, plays a deleterious role in immune-mediated demyelinating disorders including MS. Although, normally excluded from the CNS, T cells enter the CNS through a compromised blood-brain barrier in these disorders and have been shown to inhibit OL differentiation and remyelination through cytokine receptors expressed by OPCs [156-159]. Recent study demonstrates that IFN $\gamma$ induces expression of the MHC class I antigen presentation pathway in OPCs [160]. When exposed to IFN $\gamma$, OPCs switch from the constitutive proteasome to the immunoproteasome and are able to activate $\mathrm{CD} 8+\mathrm{T}$ cells, which can in turn kill the OPCs as target cells, both in vitro and in vivo [160]. In addition, several other reports show that OPCs and oligodendrocyte lineage cells in MS express transcripts associated with inflammation and antigen presentation [161, 162]. These findings reveal that under inflammatory conditions OPCs responding to local cues may not only fail to differentiate, but could actually propagate chronic inflammation. Thus, strategies targeting the aberrant immune activation pathways in OPCs may allow more efficient remyelination in MS.

\section{Effect of Aging}

Like the rest of the CNS, OLs and OPCs undergo phenotypic and functional changes with age. White matter volume begins to decline at $\sim 45$ years of age and aged OPCs in both humans and mice lose all or most of their ability to spontaneously remyelinate following demyelination [163-166]. As OPCs age, their excitability declines as a result of reduced NMDARs and voltage-gated sodium channel densities [167]. Markers of aging and senescence have also been reportedly localized to oligodendroglia in normal aging $[163,167]$ and in age-related neurodegenerative diseases [138, 164, 168]. These changes have been implicated to have a significant pathogenic role in diseases, including MS, Alzheimer's Disease (AD), dementia, and amyotrophic lateral sclerosis (ALS) $[2,163,164,169]$. In ALS, a recent study has shown an energetic dysfunction in oligodendrocyte-axonal coupling and failure of new oligodendrocytes to mature, resulting in demyelination [170]. In $\mathrm{AD}$, Zhang et al. demonstrated that senescent cells associated with the amyloid- $\beta$ plaques in $\mathrm{AD}$ patients were almost exclusively OPCs [168]. Interestingly, in a mouse model of AD treated with senolytic therapy that removed the senescent OPCs, they were able to ameliorate the amyloid- $\beta$ associated inflammation and cognitive deficits.

Several studies implicated intrinsic regulators governing OPC aging, which is thought to be partially due to altered epigenetic modifications [165, 171-174]. While others strongly suggest the environment as the primary driver of oligodendroglial aging [63]. Like most cells, OL lineage cells are sensitive to different signaling factors that may change with age. Indeed, in vivo exposure of aged OPCs to youthful growth factors through parabiosis experiments has been found to significantly improve their ability to remyelinate after experimental demyelination [149]. Similarly, aged OPCs transplanted ex vivo to synthetic scaffolds mimicking the mechanical stiffness of young extracellular matrix's (ECM) led to markedly increased proliferation and differentiation, while young OPCs transplanted to stiffer scaffolds mimicking aged ECM's resulted in the loss of their capacity to proliferate and differentiate [175]. Additionally, dysfunctional protein aggregation and clearance within the aged environment has also been shown to induce senescent OPC phenotypes, which then directly contribute to disease pathogenesis [168]. Recent studies have shown that disruption of myelin debris uptake from young macrophages impairs the rate of remyelination similarly to those seen in older mice [176]. Indeed, aged phagocytes accumulate excessive amounts of myelin debris, owing to cholesterol crystal 
formation, which results in maladaptive immune responses downstream that limit OPC differentiation [166, 177]. Interestingly, by using a heterochronic parabiosis model, Ruckh et al. was able to facilitate enhanced remyelination in older mice to that comparable to their younger counterparts by recruitment of younger macrophages that enhanced the clearance of myelin debris following demyelination [149]. Since aged OL lineage cells are implicated in many neurodegenerative diseases, determining and reversing their aging mechanisms has tremendous therapeutic potential in the repair of demyelinating diseases like MS.

\section{Concluding Remarks}

As we reviewed here, recent advances in OL biology have provided mechanistic insights into how OLs develop and regenerate in response to extrinsic signals. Heterogeneity in the OPC and OL populations adds another layer of complexity to the intricate, finely tuned regulation of myelination, which may have profound impacts on our brain function. The intrinsic differences in OPC populations may derive from their origins and include distinct transcriptomic profiles, ion channel expression and activity, varying across space and time $[167,171]$. In the adult CNS, the survival of OLs is region specific and remyelination properties of OPCs are functionally diverse [171, 178]. Moreover, the contribution of putative subpopulations of oligodendrocyte lineage cells identified in the adult brain is shifted in MS [161, 162]. A recent study using snRNA-seq demonstrated a depletion of OPCs and the intermediate OL population, but increased expression of myelin genes in mature OL in MS, which may suggest that specific subsets of mature OLs contribute to remyelination [162]. This finding is further corroborated by recent work examining the retrospectively carbon $\left({ }^{14} \mathrm{C}\right)$ dated mature oligodendrocytes from post-mortem human brain tissue of healthy and MS patients [179]. The results of this study suggest that in MS lesions myelin may be regenerated by pre-existing, and not new oligodendrocytes. However, the contribution of mature oligodendrocytes to remyelination in animal models is still debated, most likely due to the degree of oligodendrocyte survival after demyelinating injury induced by different conditions [180, 181].

Our understanding of the complexity of OL biology in the developing and adult brain is likely to increase in the near future, as techniques for the analysis of differences in cell type and function evolve and improve. Precise and distinct regulation of important steps in remyelination, with consideration of the diversity of regenerative abilities among oligodendrocyte populations, will be essential for future strategies that aim to repair and restore brain function in neurological disorders.
Funding Funding was funded by National Institute of Neurological Disorders and Stroke (Grant No.: 1R01NS107523-01), National Multiple Sclerosis Society (Grantt No.: JF-1806-31381), Congressionally Directed Medical Research Programs (Grantt No.: W81XWH-17-1-0268) and National Science Foundation (DGE0903443, Internal Grant Number: RX2700 403).

Open Access This article is licensed under a Creative Commons Attribution 4.0 International License, which permits use, sharing, adaptation, distribution and reproduction in any medium or format, as long as you give appropriate credit to the original author(s) and the source, provide a link to the Creative Commons licence, and indicate if changes were made. The images or other third party material in this article are included in the article's Creative Commons licence, unless indicated otherwise in a credit line to the material. If material is not included in the article's Creative Commons licence and your intended use is not permitted by statutory regulation or exceeds the permitted use, you will need to obtain permission directly from the copyright holder. To view a copy of this licence, visit http://creativecommons.org/licenses/by/4.0/.

\section{References}

1. Baumann N, Pham-Dinh D (2001) Biology of oligodendrocyte and myelin in the mammalian central nervous system. Physiol Rev 81:871-927

2. Rosko L, Smith VN, Yamazaki R, Huang JK (2018) Oligodendrocyte bioenergetics in health and disease. Neuroscientist. https ://doi.org/10.1177/1073858418793077

3. Ligon KL, Kesari S, Kitada M et al (2006) Development of NG2 neural progenitor cells requires Olig gene function. Proc Natl Acad Sci USA 103:7853-7858. https://doi.org/10.1073/ pnas.0511001103

4. Meijer DH, Kane MF, Mehta S et al (2012) Separated at birth? The functional and molecular divergence of OLIG1 and OLIG2. Nat Rev Neurosci 13:819-831. https://doi.org/10.1038/nrn3386

5. Kessaris N, Fogarty M, Iannarelli P et al (2006) Competing waves of oligodendrocytes in the forebrain and postnatal elimination of an embryonic lineage. Nat Neurosci 9:173-179. https ://doi.org/10.1038/nn1620

6. Zhou Q, Anderson DJ (2002) The bHLH transcription factors OLIG2 and OLIG1 couple neuronal and glial subtype specification. Cell 109:61-73. https://doi.org/10.1016/S0092 -8674(02)00677-3

7. Lu QR, Sun T, Zhu Z et al (2002) Common developmental requirement for Olig function indicates a motor neuron/oligodendrocyte connection. Cell 109:75-86

8. Takebayashi H, Nabeshima Y, Yoshida S et al (2002) The basic helix-loop-helix factor olig2 is essential for the development of motoneuron and oligodendrocyte lineages. Curr Biol 12:11571163. https://doi.org/10.1016/s0960-9822(02)00926-0

9. Bilican B, Fiore-Heriche C, Compston A et al (2008) Induction of Olig2 + precursors by FGF involves BMP signalling blockade at the smad level. PLoS ONE. https://doi.org/10.1371/journ al.pone.0002863

10. Ye F, Chen Y, Hoang T et al (2009) HDAC1 and HDAC2 regulate oligodendrocyte differentiation by disrupting the betacatenin-TCF interaction. Nat Neurosci 12:829-838. https://doi. org/10.1038/nn.2333

11. Langseth AJ, Munji RN, Choe Y et al (2010) Wnts influence the timing and efficiency of oligodendrocyte precursor cell generation in the telencephalon. J Neurosci 30:13367-13372. https:// doi.org/10.1523/JNEUROSCI.1934-10.2010 
12. Ortega JA, Radonjic NV, Zecevic N (2013) Sonic hedgehog promotes generation and maintenance of human forebrain Olig2 progenitors. Front Cell Neurosci. https://doi.org/10.3389/fncel 2013.00254

13. Barres BA, Lazar MA, Raff MC (1994) A novel role for thyroid hormone, glucocorticoids and retinoic acid in timing oligodendrocyte development. Development 120:1097-1108

14. Park H-C, Appel B (2003) Delta-Notch signaling regulates oligodendrocyte specification. Development 130:3747-3755. https ://doi.org/10.1242/dev.00576

15. Bergles DE, Richardson WD (2015) Oligodendrocyte development and plasticity. Cold Spring Harb Perspect Biol 8:a020453. https://doi.org/10.1101/cshperspect.a020453

16. Emery B, Lu QR (2015) Transcriptional and epigenetic regulation of oligodendrocyte development and myelination in the central nervous system. Cold Spring Harb Perspect Biol. https:// doi.org/10.1101/cshperspect.a020461

17. Bujalka H, Koenning M, Jackson S et al (2013) MYRF is a membrane-associated transcription factor that autoproteolytically cleaves to directly activate myelin genes. PLoS Biol. https://doi. org/10.1371/journal.pbio.1001625

18. Emery B, Agalliu D, Cahoy JD et al (2009) Myelin gene regulatory factor is a critical transcriptional regulator required for CNS myelination. Cell 138:172-185. https://doi.org/10.1016/j. cell.2009.04.031

19. Huang JK, Jarjour AA, Nait Oumesmar B et al (2011) Retinoid $\mathrm{X}$ receptor gamma signaling accelerates CNS remyelination. Nat Neurosci 14:45-53. https://doi.org/10.1038/nn.2702

20. Emery B (2010) Regulation of oligodendrocyte differentiation and myelination. Science 330:779-782. https://doi.org/10.1126/ science. 1190927

21. Barres BA, Raff MC (1999) Axonal control of oligodendrocyte development. J Cell Biol 147:1123-1128

22. Zuchero JB, Barres BA (2013) Intrinsic and extrinsic control of oligodendrocyte development. Curr Opin Neurobiol 23:914-920. https://doi.org/10.1016/j.conb.2013.06.005

23. Simons M, Trajkovic K (2006) Neuron-glia communication in the control of oligodendrocyte function and myelin biogenesis. J Cell Sci 119:4381-4389. https://doi.org/10.1242/jcs.03242

24. de Faria O, Gonsalvez DG, Nicholson M, Xiao J (2019) Activitydependent central nervous system myelination throughout life. J Neurochem 148:447-461. https://doi.org/10.1111/jnc.14592

25. Káradóttir R, Attwell D (2007) Neurotransmitter receptors in the life and death of oligodendrocytes. Neuroscience 145:14261438. https://doi.org/10.1016/j.neuroscience.2006.08.070

26. Gudz TI, Komuro H, Macklin WB (2006) Glutamate stimulates oligodendrocyte progenitor migration mediated via an $\alpha \mathrm{v}$ integrin/myelin proteolipid protein complex. J Neurosci 26:24582466. https://doi.org/10.1523/JNEUROSCI.4054-05.2006

27. Krasnow AM, Attwell D (2016) NMDA receptors: power switches for oligodendrocytes. Neuron 91:3-5. https://doi. org/10.1016/j.neuron.2016.06.023

28. Bergles DE, Roberts JDB, Somogyi P, Jahr CE (2000) Glutamatergic synapses on oligodendrocyte precursor cells in the hippocampus. Nature 405:187-191. https://doi.org/10.1038/35012 083

29. Gautier HOB, Evans KA, Volbracht K et al (2015) Neuronal activity regulates remyelination via glutamate signalling to oligodendrocyte progenitors. Nat Commun 6:8518. https://doi. org/10.1038/ncomms9518

30. Spitzer S, Volbracht K, Lundgaard I, Káradóttir RT (2016) Glutamate signalling: a multifaceted modulator of oligodendrocyte lineage cells in health and disease. Neuropharmacology 110:574-585. https://doi.org/10.1016/j.neuropharm.2016.06.014

31. Gallo V, Mangin J-M, Kukley M, Dietrich D (2008) Synapses on NG2-expressing progenitors in the brain: multiple functions?
J Physiol (Lond) 586:3767-3781. https://doi.org/10.1113/jphys iol.2008.158436

32. Gallo V, Zhou JM, McBain CJ et al (1996) Oligodendrocyte progenitor cell proliferation and lineage progression are regulated by glutamate receptor-mediated $\mathrm{K}+$ channel block. J Neurosci 16:2659-2670. https://doi.org/10.1523/JNEUROSCI.16-0802659.1996

33. Barres BA, Raff MC (1993) Proliferation of oligodendrocyte precursor cells depends on electrical activity in axons. Nature 361:258-260. https://doi.org/10.1038/361258a0

34. Demerens C, Stankoff B, Logak M et al (1996) Induction of myelination in the central nervous system by electrical activity. PNAS 93:9887-9892. https://doi.org/10.1073/pnas.93.18.9887

35. Ghiani CA, Yuan X, Eisen AM et al (1999) Voltage-activated $\mathrm{K}+$ channels and membrane depolarization regulate accumulation of the cyclin-dependent kinase inhibitors p27Kip1 and p21CIP1 in glial progenitor cells. J Neurosci 19:5380-5392. https://doi.org/10.1523/JNEUROSCI.19-13-05380.1999

36. Knutson P, Ghiani CA, Zhou J-M et al (1997) K+ channel expression and cell proliferation are regulated by intracellular sodium and membrane depolarization in oligodendrocyte progenitor cells. J Neurosci 17:2669-2682. https://doi.org/10.1523/ JNEUROSCI.17-08-02669.1997

37. Zezula J, Casaccia-Bonnefil P, Ezhevsky SA et al (2001) p21cip1 is required for the differentiation of oligodendrocytes independently of cell cycle withdrawal. EMBO Rep 2:27-34. https://doi. org/10.1093/embo-reports/kve008

38. Casaccia-Bonnefil P, Tikoo R, Kiyokawa H et al (1997) Oligodendrocyte precursor differentiation is perturbed in the absence of the cyclin-dependent kinase inhibitor p27Kip1. Genes Dev 11:2335-2346. https://doi.org/10.1101/gad.11.18.2335

39. Casaccia-Bonnefil P, Hardy RJ, Teng KK et al (1999) Loss of p27Kip1 function results in increased proliferative capacity of oligodendrocyte progenitors but unaltered timing of differentiation. Development 126:4027-4037

40. Ghiani CA, Gallo V (2001) Inhibition of cyclin E-cyclin-dependent kinase 2 complex formation and activity is associated with cell cycle arrest and withdrawal in oligodendrocyte progenitor cells. J Neurosci 21:1274-1282. https://doi.org/10.1523/JNEUR OSCI.21-04-01274.2001

41. Casaccia-Bonnefil P, Liu A (2003) Relationship between cell cycle molecules and onset of oligodendrocyte differentiation. J Neurosci Res 72:1-11. https://doi.org/10.1002/jnr.10565

42. Nguyen L, Borgs L, Vandenbosch R et al (2006) The Yin and Yang of cell cycle progression and differentiation in the oligodendroglial lineage. Mental Retardation Dev Disabil Res Rev 12:85-96. https://doi.org/10.1002/mrdd.20103

43. Lyssiotis CA, Walker J, Wu C et al (2007) Inhibition of histone deacetylase activity induces developmental plasticity in oligodendrocyte precursor cells. PNAS 104:14982-14987. https://doi. org/10.1073/pnas.0707044104

44. Marin-Husstege M, Muggironi M, Liu A, Casaccia-Bonnefil P (2002) Histone deacetylase activity is necessary for oligodendrocyte lineage progression. J Neurosci 22:10333-10345. https ://doi.org/10.1523/JNEUROSCI.22-23-10333.2002

45. Kondo T, Raff M (2004) Chromatin remodeling and histone modification in the conversion of oligodendrocyte precursors to neural stem cells. Genes Dev 18:2963-2972. https://doi.org/10.1101/ gad.309404

46. Gao F-B, Apperly J, Raff M (1998) Cell-intrinsic timers and thyroid hormone regulate the probability of cell-cycle withdrawal and differentiation of oligodendrocyte precursor cells. Developmental Biology 197:54-66. https://doi.org/10.1006/ dbio. 1998.8877 
47. Ziskin JL, Nishiyama A, Rubio M et al (2007) Vesicular release of glutamate from unmyelinated axons in white matter. Nat Neurosci 10:321-330. https://doi.org/10.1038/nn1854

48. Wake H, Lee PR, Fields RD (2011) Control of local protein synthesis and initial events in myelination by action potentials. Science 333:1647-1651. https://doi.org/10.1126/science.1206998

49. Wake H, Ortiz FC, Woo DH et al (2015) Nonsynaptic junctions on myelinating glia promote preferential myelination of electrically active axons. Nat Commun 6:7844. https://doi.org/10.1038/ ncomms 8844

50. Gibson EM, Purger D, Mount CW et al (2014) Neuronal activity promotes oligodendrogenesis and adaptive myelination in the mammalian brain. Science 344:1252304. https://doi.org/10.1126/ science. 1252304

51. Hines JH, Ravanelli AM, Schwindt R et al (2015) Neuronal activity biases axon selection for myelination in vivo. Nat Neurosci 18:683-689. https://doi.org/10.1038/nn.3992

52. Mitew S, Gobius I, Fenlon LR et al (2018) Pharmacogenetic stimulation of neuronal activity increases myelination in an axonspecific manner. Nat Commun 9:1-16. https://doi.org/10.1038/ s41467-017-02719-2

53. Fields RD (2015) A new mechanism of nervous system plasticity: activity-dependent myelination. Nat Rev Neurosci 16:756-767. https://doi.org/10.1038/nrn4023

54. Koudelka S, Voas MG, Almeida RG et al (2016) Individual neuronal subtypes exhibit diversity in CNS myelination mediated by synaptic vesicle release. Curr Biol 26:1447-1455. https://doi. org/10.1016/j.cub.2016.03.070

55. Hamilton NB, Clarke LE, Arancibia-Carcamo IL et al (2017) Endogenous GABA controls oligodendrocyte lineage cell number, myelination, and CNS internode length. Glia 65:309-321. https://doi.org/10.1002/glia.23093

56. Luyt K, Slade TP, Dorward JJ et al (2007) Developing oligodendrocytes express functional GABAB receptors that stimulate cell proliferation and migration. J Neurochem 100:822-840. https:// doi.org/10.1111/j.1471-4159.2006.04255.x

57. Hughes EG, Kang SH, Fukaya M, Bergles DE (2013) Oligodendrocyte progenitors balance growth with self-repulsion to achieve homeostasis in the adult brain. Nat Neurosci 16:668-676. https ://doi.org/10.1038/nn.3390

58. McKenzie IA, Ohayon D, Li H et al (2014) Motor skill learning requires active central myelination. Science 346:318-322. https ://doi.org/10.1126/science. 1254960

59. Xiao L, Ohayon D, McKenzie IA et al (2016) Rapid production of new oligodendrocytes is required in the earliest stages of motor-skill learning. Nat Neurosci 19:1210-1217. https://doi. org/10.1038/nn.4351

60. Zhao Y-Y, Shi X-Y, Qiu X et al (2012) Enriched environment increases the myelinated nerve fibers of aged rat corpus callosum. Anat Rec 295:999-1005. https://doi.org/10.1002/ar.22446

61. Liu J, Dietz K, DeLoyht JM et al (2012) Impaired adult myelination in the prefrontal cortex of socially isolated mice. Nat Neurosci 15:1621-1623. https://doi.org/10.1038/nn.3263

62. Makinodan M, Rosen KM, Ito S, Corfas G (2012) A critical period for social experience-dependent oligodendrocyte maturation and myelination. Science 337:1357-1360. https://doi. org/10.1126/science.1220845

63. Forbes TA, Gallo V (2017) All wrapped up: environmental effects on myelination. Trends Neurosci 40:572-587. https:// doi.org/10.1016/j.tins.2017.06.009

64. Raff MC, Lillien LE, Richardson WD et al (1988) Plateletderived growth factor from astrocytes drives the clock that times oligodendrocyte development in culture. Nature 333:562-565. https://doi.org/10.1038/333562a0
65. Bansal R, Kumar M, Murray K et al (1996) Regulation of FGF receptors in the oligodendrocyte lineage. Mol Cell Neurosci 7:263-275. https://doi.org/10.1006/mcne.1996.0020

66. Bansal R, Magge S, Winkler S (2003) Specific inhibitor of FGF receptor signaling: FGF-2-mediated effects on proliferation, differentiation, and MAPK activation are inhibited by PD173074 in oligodendrocyte-lineage cells. J Neurosci Res 74:486-493. https ://doi.org/10.1002/jnr.10773

67. Kahn MA, De Vellis J (1994) Regulation of an oligodendrocyte progenitor cell line by the interleukin- 6 family of cytokines. Glia 12:87-98. https://doi.org/10.1002/glia.440120202

68. Ishibashi T, Lee PR, Baba H, Fields RD (2009) Leukemia inhibitory factor regulates the timing of oligodendrocyte development and myelination in the postnatal optic nerve. J Neurosci Res 87:3343-3355. https://doi.org/10.1002/jnr.22173

69. Ishibashi T, Dakin KA, Stevens B et al (2006) Astrocytes promote myelination in response to electrical impulses. Neuron 49:823-832. https://doi.org/10.1016/j.neuron.2006.02.006

70. Liedtke W, Edelmann W, Bieri PL et al (1996) GFAP is necessary for the integrity of CNS white matter architecture and longterm maintenance of myelination. Neuron 17:607-615. https:// doi.org/10.1016/s0896-6273(00)80194-4

71. Fruttiger M, Karlsson L, Hall AC et al (1999) Defective oligodendrocyte development and severe hypomyelination in PDGF-A knockout mice. Development 126:457-467

72. Fruttiger M, Calver AR, Richardson WD (2000) Platelet-derived growth factor is constitutively secreted from neuronal cell bodies but not from axons. Curr Biol 10:1283-1286. https://doi. org/10.1016/s0960-9822(00)00757-0

73. Bögler O, Wren D, Barnett SC et al (1990) Cooperation between two growth factors promotes extended self-renewal and inhibits differentiation of oligodendrocyte-type-2 astrocyte (O-2A) progenitor cells. Proc Natl Acad Sci USA 87:6368-6372. https://doi. org/10.1073/pnas.87.16.6368

74. Gadea A, Aguirre A, Haydar TF, Gallo V (2009) Endothelin-1 regulates oligodendrocyte development. J Neurosci 29:1004710062. https://doi.org/10.1523/JNEUROSCI.0822-09.2009

75. MacCumber MW, Ross CA, Snyder SH (1990) Endothelin in brain: receptors, mitogenesis, and biosynthesis in glial cells. PNAS 87:2359-2363

76. Yuen TJ, Johnson KR, Miron VE et al (2013) Identification of endothelin 2 as an inflammatory factor that promotes central nervous system remyelination. Brain 136:1035-1047. https:// doi.org/10.1093/brain/awt024

77. Kiray H, Lindsay SL, Hosseinzadeh S, Barnett SC (2016) The multifaceted role of astrocytes in regulating myelination. Exp Neurol 283:541-549. https://doi.org/10.1016/j.expne urol.2016.03.009

78. Blaschuk KL, Frost EE, Ffrench-Constant C (2000) The regulation of proliferation and differentiation in oligodendrocyte progenitor cells by alphaV integrins. Development 127:1961-1969

79. Milner R, Edwards G, Streuli C, Ffrench-Constant C (1996) A role in migration for the alpha $\mathrm{V}$ beta 1 integrin expressed on oligodendrocyte precursors. J Neurosci 16:7240-7252

80. Baron W, Shattil SJ, Ffrench-Constant C (2002) The oligodendrocyte precursor mitogen PDGF stimulates proliferation by activation of $\alpha v \beta 3$ integrins. EMBO J 21:1957-1966. https:// doi.org/10.1093/emboj/21.8.1957

81. Baron W, Colognato H, Ffrench-Constant C (2005) Integringrowth factor interactions as regulators of oligodendroglial development and function. Glia 49:467-479. https://doi. org/10.1002/glia.20132

82. Oh LY, Yong VW (1996) Astrocytes promote process outgrowth by adult human oligodendrocytes in vitro through interaction between bFGF and astrocyte extracellular matrix. Glia 
17:237-253. https://doi.org/10.1002/(SICI)1098-1136(19960 7) $17: 3 \% 3 c 237: A I D-G L I A 6 \% 3 e 3.0 . C O ; 2-Y$

83. Oh LY, Goodyer CG, Olivier A, Yong VW (1997) The promoting effects of bFGF and astrocyte extracellular matrix on process outgrowth by adult human oligodendrocytes are mediated by protein kinase C. Brain Res 757:236-244. https://doi.org/10.1016/s0006 -8993(97)00224-2

84. Liu Y, Given KS, Dickson EL et al (2019) Concentration-dependent effects of CSF1R inhibitors on oligodendrocyte progenitor cells ex vivo and in vivo. Exp Neurol 318:32-41. https://doi. org/10.1016/j.expneurol.2019.04.011

85. Miron VE, Franklin RJM (2014) Macrophages and CNS remyelination. J Neurochem 130:165-171. https://doi.org/10.1111/ jnc. 12705

86. Miron VE, Boyd A, Zhao J-W et al (2013) M2 microglia and macrophages drive oligodendrocyte differentiation during CNS remyelination. Nat Neurosci 16:1211-1218. https://doi. org/10.1038/nn.3469

87. Pang Y, Fan L-W, Tien L-T et al (2013) Differential roles of astrocyte and microglia in supporting oligodendrocyte development and myelination in vitro. Brain Behav 3:503-514. https:// doi.org/10.1002/brb3.152

88. Fischer AJ, Zelinka C, Gallina D et al (2014) Reactive microglia and macrophage facilitate the formation of Müller glia-derived retinal progenitors. Glia 62:1608-1628. https://doi.org/10.1002/ glia.22703

89. Vela JM, Molina-Holgado E, Arévalo-Martín A et al (2002) Interleukin-1 regulates proliferation and differentiation of oligodendrocyte progenitor cells. Mol Cell Neurosci 20:489-502

90. Patel JR, Williams JL, Muccigrosso MM et al (2012) Astrocyte TNFR2 is required for CXCL12-mediated regulation of oligodendrocyte progenitor proliferation and differentiation within the adult CNS. Acta Neuropathol 124:847-860. https://doi. org/10.1007/s00401-012-1034-0

91. Shigemoto-Mogami Y, Hoshikawa K, Goldman JE et al (2014) Microglia enhance neurogenesis and oligodendrogenesis in the early postnatal subventricular zone. J Neurosci 34:2231-2243. https://doi.org/10.1523/JNEUROSCI.1619-13.2014

92. Ashwell K (1990) Microglia and cell death in the developing mouse cerebellum. Brain Res Dev Brain Res 55:219-230. https ://doi.org/10.1016/0165-3806(90)90203-b

93. Bauer HC, Bauer H, Lametschwandtner A et al (1993) Neovascularization and the appearance of morphological characteristics of the blood-brain barrier in the embryonic mouse central nervous system. Brain Res Dev Brain Res 75:269-278. https://doi. org/10.1016/0165-3806(93)90031-5

94. Vanlandewijck M, He L, Mäe MA et al (2018) A molecular atlas of cell types and zonation in the brain vasculature. Nature 554:475-480. https://doi.org/10.1038/nature25739

95. He L, Vanlandewijck M, Raschperger E et al (2016) Analysis of the brain mural cell transcriptome. Sci Rep 6:35108. https://doi. org/10.1038/srep35108

96. He L, Vanlandewijck M, Mäe MA et al (2018) Single-cell RNA sequencing of mouse brain and lung vascular and vessel-associated cell types. Sci Data 5:180160. https://doi.org/10.1038/sdata .2018 .160

97. Yuen TJ, Silbereis JC, Griveau A et al (2014) Oligodendrocyteencoded HIF function couples postnatal myelination and white matter angiogenesis. Cell 158:383-396. https://doi.org/10.1016/j. cell.2014.04.052

98. Mishra S, Choe Y, Pleasure SJ, Siegenthaler JA (2016) Cerebrovascular defects in Foxc1 mutants correlate with aberrant WNT and VEGF-A pathways downstream of retinoic acid from the meninges. Dev Biol 420:148-165. https://doi.org/10.1016/j. ydbio.2016.09.019
99. Chintawar S, Hourez R, Ravella A et al (2009) Grafting neural precursor cells promotes functional recovery in an SCA1 mouse model. J Neurosci 29:13126-13135. https://doi.org/10.1523/ JNEUROSCI.0647-09.2009

100. Arai K, Lo EH (2009) An oligovascular niche: cerebral endothelial cells promote the survival and proliferation of oligodendrocyte precursor cells. J Neurosci 29:4351-4355. https://doi. org/10.1523/JNEUROSCI.0035-09.2009

101. Plane JM, Andjelkovic AV, Keep RF, Parent JM (2010) Intact and injured endothelial cells differentially modulate postnatal murine forebrain neural stem cells. Neurobiol Dis 37:218-227. https:// doi.org/10.1016/j.nbd.2009.10.008

102. Silva ME, Lange S, Hinrichsen B et al (2019) Pericytes favor oligodendrocyte fate choice in adult neural stem cells. Front Cell Neurosci. https://doi.org/10.3389/fncel.2019.00085

103. Tsai H-H, Niu J, Munji R et al (2016) Oligodendrocyte precursors migrate along vasculature in the developing nervous system. Science 351:379-384. https://doi.org/10.1126/science.aad3839

104. Maki T, Maeda M, Uemura M et al (2015) Potential interactions between pericytes and oligodendrocyte precursor cells in perivascular regions of cerebral white matter. Neurosci Lett 597:164-169. https://doi.org/10.1016/j.neulet.2015.04.047

105. De La Fuente AG, Lange S, Silva ME et al (2017) Pericytes stimulate oligodendrocyte progenitor cell differentiation during CNS remyelination. Cell Rep 20:1755-1764. https://doi.org/10.1016/j. celrep.2017.08.007

106. Kurachi M, Mikuni M, Ishizaki Y (2016) Extracellular vesicles from vascular endothelial cells promote survival, proliferation and motility of oligodendrocyte precursor cells. PLoS ONE 11:e0159158. https://doi.org/10.1371/journal.pone.0159158

107. Osawa S, Kurachi M, Yamamoto H et al (2017) Fibronectin on extracellular vesicles from microvascular endothelial cells is involved in the vesicle uptake into oligodendrocyte precursor cells. Biochem Biophys Res Commun 488:232-238. https://doi. org/10.1016/j.bbrc.2017.05.049

108. Rivers LE, Young KM, Rizzi M et al (2008) PDGFRA/NG2 glia generate myelinating oligodendrocytes and piriform projection neurons in adult mice. Nat Neurosci 11:1392-1401. https://doi. org/10.1038/nn.2220

109. Pringle NP, Mudhar HS, Collarini EJ, Richardson WD (1992) PDGF receptors in the rat CNS: during late neurogenesis, PDGF alpha-receptor expression appears to be restricted to glial cells of the oligodendrocyte lineage. Development 115:535-551

110. Calver AR, Hall AC, Yu WP et al (1998) Oligodendrocyte population dynamics and the role of PDGF in vivo. Neuron 20:869882. https://doi.org/10.1016/s0896-6273(00)80469-9

111. Nishiyama A, Chang A, Trapp BD (1999) NG2 + glial cells: a novel glial cell population in the adult brain. J Neuropathol Exp Neurol 58:1113-1124. https://doi.org/10.1097/00005072-19991 1000-00001

112. Nishiyama A, Dahlin KJ, Prince JT et al (1991) The primary structure of NG2, a novel membrane-spanning proteoglycan. J Cell Biol 114:359-371. https://doi.org/10.1083/jcb.114.2.359

113. Dimou L, Gallo V (2015) NG2-glia and their functions in the central nervous system. Glia 63:1429-1451. https://doi. org/10.1002/glia.22859

114. Nishiyama A (2007) Polydendrocytes: NG2 cells with many roles in development and repair of the CNS. Neuroscientist 13:62-76. https://doi.org/10.1177/1073858406295586

115. Leonetti C, Macrez R, Pruvost M et al (2017) Tissue-type plasminogen activator exerts EGF-like chemokinetic effects on oligodendrocytes in white matter (re)myelination. Mol Neurodegener 12:20. https://doi.org/10.1186/s13024-017-0160-5 
116. Correa F, Gauberti M, Parcq J et al (2011) Tissue plasminogen activator prevents white matter damage following stroke. J Exp Med 208:1229-1242. https://doi.org/10.1084/jem.20101880

117. Hayakawa K, Pham L-DD, Som AT et al (2011) Vascular endothelial growth factor regulates the migration of oligodendrocyte precursor cells. J Neurosci 31:10666-10670. https://doi. org/10.1523/JNEUROSCI.1944-11.2011

118. Aguirre A, Dupree JL, Mangin JM, Gallo V (2007) A functional role for EGFR signaling in myelination and remyelination. Nat Neurosci 10:990-1002. https://doi.org/10.1038/nn1938

119. Niu J, Tsai H-H, Hoi KK et al (2019) Aberrant oligodendroglialvascular interactions disrupt the blood-brain barrier, triggering CNS inflammation. Nat Neurosci 22:709-718. https://doi. org/10.1038/s41593-019-0369-4

120. Kinney HC, Back SA (1998) Human oligodendroglial development: relationship to periventricular leukomalacia. Semin Pediatr Neurol 5:180-189

121. Back SA, Luo NL, Borenstein NS et al (2001) Late Oligodendrocyte progenitors coincide with the developmental window of vulnerability for human perinatal white matter injury. J Neurosci 21:1302-1312. https://doi.org/10.1523/JNEUROSCI.2104-01302.2001

122. Back SA, Han BH, Luo NL et al (2002) selective vulnerability of late oligodendrocyte progenitors to hypoxia-ischemia. J Neurosci 22:455-463. https://doi.org/10.1523/JNEUR OSCI.22-02-00455.2002

123. Salmaso N, Jablonska B, Scafidi J et al (2014) Neurobiology of premature brain injury. Nat Neurosci 17:341-346. https:// doi.org/10.1038/nn.3604

124. Jablonska B, Scafidi J, Aguirre A et al (2012) Oligodendrocyte regeneration after neonatal hypoxia requires FoxO1-mediated p27Kip1 expression. J Neurosci 32:14775-14793. https://doi. org/10.1523/JNEUROSCI.2060-12.2012

125. Jablonska B, Aguirre A, Vandenbosch R et al (2007) Cdk2 is critical for proliferation and self-renewal of neural progenitor cells in the adult subventricular zone. The Journal of Cell Biology 179:1231-1245. https://doi.org/10.1083/jcb.200702031

126. Jablonska B, Gierdalski M, Chew L-J et al (2016) Sirt1 regulates glial progenitor proliferation and regeneration in white matter after neonatal brain injury. Nat Commun 7:13866. https ://doi.org/10.1038/ncomms13866

127. Scafidi J, Hammond TR, Scafidi S et al (2014) Intranasal epidermal growth factor treatment rescues neonatal brain injury. Nature 506:230-234. https://doi.org/10.1038/nature12880

128. Compston A, Coles A (2002) Multiple sclerosis. Lancet 359:1221-1231. https://doi.org/10.1016/S0140-6736(02)08220 $-\mathrm{X}$

129. Lassmann H, van Horssen J, Mahad D (2012) Progressive multiple sclerosis: pathology and pathogenesis. Nat Rev Neurol 8:647-656. https://doi.org/10.1038/nrneurol.2012.168

130. Dutta R, Trapp BD (2011) Mechanisms of neuronal dysfunction and degeneration in multiple sclerosis. Prog Neurobiol 93:1-12. https://doi.org/10.1016/j.pneurobio.2010.09.005

131. Dutta R, Trapp BD (2014) Relapsing and progressive forms of multiple sclerosis: insights from pathology. Curr Opin Neurol 27:271-278. https://doi.org/10.1097/WCO.000000000000009 4

132. Reich DS, Lucchinetti CF, Calabresi PA (2018) Multiple Sclerosis. N Engl J Med 378:169-180. https://doi.org/10.1056/NEJMr a1401483

133. Franklin RJM, Ffrench-Constant C (2008) Remyelination in the CNS: from biology to therapy. Nat Rev Neurosci 9:839-855. https://doi.org/10.1038/nrn2480

134. Franklin RJM, Gallo V (2014) The translational biology of remyelination: past, present, and future. Glia 62:1905-1915. https:// doi.org/10.1002/glia.22622
135. Franklin RJM (2002) Why does remyelination fail in multiple sclerosis? Nat Rev Neurosci 3:705-714. https://doi.org/10.1038/ nrn917

136. Chang A, Tourtellotte WW, Rudick R, Trapp BD (2002) Premyelinating oligodendrocytes in chronic lesions of multiple sclerosis. N Engl J Med 346:165-173. https://doi.org/10.1056/NEJMo a010994

137. Wolswijk G (2000) Oligodendrocyte survival, loss and birth in lesions of chronic-stage multiple sclerosis. Brain $123(\mathrm{Pt}$ 1):105-115

138. Wolswijk G (1998) Chronic stage multiple sclerosis lesions contain a relatively quiescent population of oligodendrocyte precursor cells. J Neurosci 18:601-609

139. Huang JK, Franklin RJM (2012) Current status of myelin replacement therapies in multiple sclerosis. Prog Brain Res 201:219231. https://doi.org/10.1016/B978-0-444-59544-7.00011-1

140. Domingues HS, Portugal CC, Socodato R, Relvas JB (2016) Oligodendrocyte, astrocyte, and microglia crosstalk in myelin development, damage, and repair. Front Cell Dev Biol. https:// doi.org/10.3389/fcell.2016.00071

141. Nash B, Thomson CE, Linington $C$ et al (2011) Functional duality of astrocytes in myelination. J Neurosci 31:13028-13038. https://doi.org/10.1523/JNEUROSCI.1449-11.2011

142. Hammond TR, Gadea A, Dupree J et al (2014) Astrocytederived Endothelin-1 inhibits remyelination through Notch activation. Neuron 81:588-602. https://doi.org/10.1016/j.neuro n.2013.11.015

143. Genoud S, Lappe-Siefke C, Goebbels S et al (2002) Notch1 control of oligodendrocyte differentiation in the spinal cord. J Cell Biol 158:709-718. https://doi.org/10.1083/jcb.200202002

144. Zhang Y, Argaw AT, Gurfein BT et al (2009) Notch1 signaling plays a role in regulating precursor differentiation during CNS remyelination. Proc Natl Acad Sci USA 106:19162-19167. https ://doi.org/10.1073/pnas.0902834106

145. Gadea A, Schinelli S, Gallo V (2008) Endothelin-1 regulates astrocyte proliferation and reactive gliosis via a JNK/c-Jun signaling pathway. J Neurosci 28:2394-2408. https://doi.org/10.1523/ JNEUROSCI.5652-07.2008

146. Hammond TR, McEllin B, Morton PD et al (2015) Endothelin$\mathrm{B}$ receptor activation in astrocytes regulates the rate of oligodendrocyte regeneration during remyelination. Cell Reports 13:2090-2097. https://doi.org/10.1016/j.celrep.2015.11.002

147. Kotter MR, Setzu A, Sim FJ et al (2001) Macrophage depletion impairs oligodendrocyte remyelination following lysolecithininduced demyelination. Glia 35:204-212

148. Kotter MR, Li W-W, Zhao C, Franklin RJM (2006) Myelin impairs CNS remyelination by inhibiting oligodendrocyte precursor cell differentiation. J Neurosci 26:328-332. https://doi. org/10.1523/JNEUROSCI.2615-05.2006

149. Ruckh JM, Zhao J-W, Shadrach JL et al (2012) Rejuvenation of regeneration in the aging central nervous system. Cell Stem Cell 10:96-103. https://doi.org/10.1016/j.stem.2011.11.019

150. Edwards JP, Zhang X, Frauwirth KA, Mosser DM (2006) Biochemical and functional characterization of three activated macrophage populations. J Leukoc Biol 80:1298-1307. https://doi. org/10.1189/jlb.0406249

151. Guardiola-Diaz HM, Ishii A, Bansal R (2012) Erk1/2 MAPK and mTOR signaling sequentially regulates progression through distinct stages of oligodendrocyte differentiation. Glia 60:476-486. https://doi.org/10.1002/glia.22281

152. Gosselin D, Skola D, Coufal NG et al (2017) An environmentdependent transcriptional network specifies human microglia identity. Science. https://doi.org/10.1126/science.aal3222

153. Butovsky O, Weiner HL (2018) Microglial signatures and their role in health and disease. Nat Rev Neurosci 19:622-635. https ://doi.org/10.1038/s41583-018-0057-5 
154. Pulido-Salgado M, Vidal-Taboada JM, Barriga GG-D et al (2018) RNA-Seq transcriptomic profiling of primary murine microglia treated with LPS or LPS + IFN $\gamma$. Sci Rep 8:1-21. https://doi. org/10.1038/s41598-018-34412-9

155. Psachoulia K, Chamberlain KA, Heo D et al (2016) IL4I1 augments CNS remyelination and axonal protection by modulating T cell driven inflammation. Brain 139:3121-3136. https://doi. org/10.1093/brain/aww254

156. Chew L-J, King WC, Kennedy A, Gallo V (2005) Interferon- $\gamma$ inhibits cell cycle exit in differentiating oligodendrocyte progenitor cells. Glia 52:127-143. https://doi.org/10.1002/glia.20232

157. Baerwald KD, Popko B (1998) Developing and mature oligodendrocytes respond differently to the immune cytokine interferongamma. J Neurosci Res 52:230-239

158. Lin W, Kemper A, Dupree JL et al (2006) Interferon-gamma inhibits central nervous system remyelination through a process modulated by endoplasmic reticulum stress. Brain 129:13061318. https://doi.org/10.1093/brain/awl044

159. Babbe H, Roers A, Waisman A et al (2000) Clonal Expansions of $\mathrm{Cd} 8+\mathrm{T}$ cells dominate the $\mathrm{T}$ cell infiltrate in active multiple sclerosis lesions as shown by micromanipulation and single cell polymerase chain reaction. J Exp Med 192:393-404. https://doi. org/10.1084/jem.192.3.393

160. Kirby L, Jin J, Cardona JG et al (2019) Oligodendrocyte precursor cells present antigen and are cytotoxic targets in inflammatory demyelination. Nat Commun 10:1-20. https://doi.org/10.1038/ s41467-019-11638-3

161. Falcão AM, van Bruggen D, Marques S et al (2018) Disease-specific oligodendrocyte lineage cells arise in multiple sclerosis. Nat Med 24:1837-1844. https://doi.org/10.1038/s41591-018-0236-y

162. Jäkel S, Agirre E, Falcão AM et al (2019) Altered human oligodendrocyte heterogeneity in multiple sclerosis. Nature 566:543547. https://doi.org/10.1038/s41586-019-0903-2

163. Tse K-H, Herrup K (2017) DNA damage in the oligodendrocyte lineage and its role in brain aging. Mech Ageing Dev 161:37-50. https://doi.org/10.1016/J.MAD.2016.05.006

164. Nicaise AM, Wagstaff LJ, Willis CM et al (2019) Cellular senescence in progenitor cells contributes to diminished remyelination potential in progressive multiple sclerosis. Proc Natl Acad Sci USA 116:9030-9039. https://doi.org/10.1073/pnas.1818348116

165. Shen S, Liu A, Li J et al (2008) Epigenetic memory loss in aging oligodendrocytes in the corpus callosum. Neurobiol Aging 29:452-463. https://doi.org/10.1016/J.NEUROBIOLA GING.2006.10.026

166. Cantuti-Castelvetri L, Fitzner D, Bosch-Queralt M et al (2018) Defective cholesterol clearance limits remyelination in the aged central nervous system. Science 359:684-688. https://doi. org/10.1126/science.aan4183

167. Spitzer SO, Sitnikov S, Kamen Y et al (2019) Oligodendrocyte progenitor cells become regionally diverse and heterogeneous with age. Neuron 101:459-471.e5. https://doi.org/10.1016/j. neuron.2018.12.020

168. Zhang P, Kishimoto Y, Grammatikakis I et al (2019) Senolytic therapy alleviates $A \beta$-associated oligodendrocyte progenitor cell senescence and cognitive deficits in an Alzheimer's disease model. Nat Neurosci 22:719-728. https://doi.org/10.1038/s4159 3-019-0372-9
169. Lee Y, Morrison BM, Li Y et al (2012) Oligodendroglia metabolically support axons and contribute to neurodegeneration. Nature 487:443-448. https://doi.org/10.1038/nature11314

170. Kang SH, Li Y, Fukaya M et al (2013) Degeneration and impaired regeneration of gray matter oligodendrocytes in amyotrophic lateral sclerosis. Nat Neurosci 16:571-579. https://doi. org/10.1038/nn.3357

171. Foerster S, Hill MFE, Franklin RJM (2019) Diversity in the oligodendrocyte lineage: plasticity or heterogeneity? Glia. https:// doi.org/10.1002/glia.23607

172. Viganò F, Möbius W, Götz M, Dimou L (2013) Transplantation reveals regional differences in oligodendrocyte differentiation in the adult brain. Nat Neurosci 16:1370-1372. https://doi. org/10.1038/nn.3503

173. Crawford AH, Tripathi RB, Richardson WD, Franklin RJM (2016) Developmental origin of oligodendrocyte lineage cells determines response to demyelination and susceptibility to ageassociated functional decline. Cell Rep 15:761-773. https://doi. org/10.1016/j.celrep.2016.03.069

174. Chari DM, Crang AJ, Blakemore WF (2003) Decline in rate of colonization of oligodendrocyte progenitor Cell (OPC)-depleted tissue by adult OPCs with age. J Neuropathol Exp Neurol 62:908-916. https://doi.org/10.1093/jnen/62.9.908

175. Segel M, Neumann B, Hill MFE et al (2019) Niche stiffness underlies the ageing of central nervous system progenitor cells. Nature 573:130-134. https://doi.org/10.1038/s41586-019-1484-9

176. Natrajan MS, de la Fuente AG, Crawford AH et al (2015) Retinoid $\mathrm{X}$ receptor activation reverses age-related deficiencies in myelin debris phagocytosis and remyelination. Brain 138:35813597. https://doi.org/10.1093/brain/awv289

177. Chen Y, Popko B (2018) Cholesterol crystals impede nerve repair. Science 359:635-636. https://doi.org/10.1126/scien ce.aar7369

178. Tripathi RB, Clarke LE, Burzomato V et al (2011) Dorsally and ventrally derived oligodendrocytes have similar electrical properties but myelinate preferred tracts. J Neurosci 31:6809-6819. https://doi.org/10.1523/JNEUROSCI.6474-10.2011

179. Yeung MSY, Djelloul M, Steiner E et al (2019) Dynamics of oligodendrocyte generation in multiple sclerosis. Nature 566:538542. https://doi.org/10.1038/s41586-018-0842-3

180. Duncan ID, Radcliff AB, Heidari M et al (2018) The adult oligodendrocyte can participate in remyelination. Proc Natl Acad Sci USA 115:E11807-E11816. https://doi.org/10.1073/pnas.18080 64115

181. Crawford AH, Tripathi RB, Foerster S et al (2016) Pre-existing mature oligodendrocytes do not contribute to remyelination following toxin-induced spinal cord demyelination. Am J Pathol 186:511-516. https://doi.org/10.1016/j.ajpath.2015.11.005

Publisher's Note Springer Nature remains neutral with regard to jurisdictional claims in published maps and institutional affiliations. 